\title{
Management in primary care at the time of a suicide attempt and its impact on care post-suicide attempt: an observational study in the French GP sentinel surveillance system
}

Nadia Younes ${ }^{1,2,3^{*}}$, Mathieu Rivière ${ }^{4,5}$, Frédéric Urbain ${ }^{3}$, Romain Pons ${ }^{4,5}$, Thomas Hanslik ${ }^{4,5}$, Louise Rossignol ${ }^{4}$, Christine Chan Chee ${ }^{6}$ and Thierry Blanchon ${ }^{4}$

\begin{abstract}
Background: We aimed to describe primary care management at the time of a suicide attempt (SA) and after the SA. Methods: An observational (cross-sectional) study was conducted among 166 sentinel GPs within France (a nongatekeeping country) between 2013 and 2017 for all GP's patients who attempted suicide. Measurements: frequency of patients 1) managed by the GP at the time of the SA, 2) addressed to an emergency department (ED), 3) without care at the time of the SA, and 4) managed by the GP after the SA and factors associated with GP management at the time of and after the SA.

Results: Three hundred twenty-one SAs were reported, of which $N=95$ (29.6\%) were managed by the GP at the time of the $\mathrm{SA}, \mathrm{N}=(70.5 \%)$ were referred to an $\mathrm{ED}$, and $\mathrm{N}=(27.4 \%)$ remained at home. Forty-eight (14.9\%) patients did not receive any care at the time of the SA and 178 (55.4\%) were managed directly by an ED. GPs were more likely to be involved in management of the patient at the time of the SA if they were younger ( $39.2 \%$ for patients < 34 years old; $22.9 \%$ for those 35 to 54 years old, and $30.3 \%$ for those more than 55 years old $p=0.02$ ) or the SA involved a firearm or self-cutting (51.9\%) versus those involving drugs (23.7\%); $p=0.006)$. After the SA, GPs managed 174 patients (54.2\%), more often (60\%) when they provided care at home at the time of the SA, $p=0.04 ; 1.87[1.07 ; 3.35]$. No other factor was associated with management by GPs after the SA.

(Continued on next page)
\end{abstract}

\footnotetext{
* Correspondence: nyounes@ch-versailles.fr

'EA 40-47 Université Versailles Saint-Quentin-en-Yvelines, F-78047 Guyancourt, France

${ }^{2}$ Versailles Hospital, Academic Unit of Psychiatry, 177 Rue de Versailles, 78157 Le Chesnay, Cedex, France

Full list of author information is available at the end of the article
}

C C The Author(s). 2020 Open Access This article is licensed under a Creative Commons Attribution 4.0 International License, which permits use, sharing, adaptation, distribution and reproduction in any medium or format, as long as you give appropriate credit to the original author(s) and the source, provide a link to the Creative Commons licence, and indicate if changes were made. The images or other third party material in this article are included in the article's Creative Commons licence, unless indicated otherwise in a credit line to the material. If material is not included in the article's Creative Commons licence and your intended use is not permitted by statutory regulation or exceeds the permitted use, you will need to obtain permission directly from the copyright holder. To view a copy of this licence, visit http://creativecommons.org/licenses/by/4.0/. The Creative Commons Public Domain Dedication waiver (http://creativecommons.org/publicdomain/zero/1.0/) applies to the data made available in this article, unless otherwise stated in a credit line to the data. 
(Continued from previous page)

Conclusions: The study faced limitations: data were not available for patients managed solely by specialists during their SA and results may not be generalisable to countries with a stronger gatekeeping system. We concluded that GPS are involved in the management of patients at the time of a SA for a third of patients. EDs are the major provider of care at that time. Half patients consulted GPs after the SA and connections between GPs and ED upon discharge should be improved.

Keywords: Suicide prevention, General practice, Suicide attempts, Management of the suicide attempt, Post-suicide attempt care

\section{Background}

Suicidal behaviour has been identified as a major public health issue worldwide [1]. In France, 195,000 suicide attempts (SA) [2, 3] and 10,000 suicides (incidence rate 18.0/100,000 inhabitants) [4] are reported per year. This is among the highest incidence rates in Europe.

GPs play a central role in suicide prevention and the management of suicidal patients. Suicidal behaviours are frequent in primary care: 2.4 to $8 \%$ of primary care patients have suicidal thoughts $[5,6]$ and a GP encounters one to six SAs in a working year $[7,8]$ and loses a patient by suicide every four to 7 years $[7,9]$. Among patients with depressive disorders, $10.4 \%$ attempted suicide during the last 5 years [10]. At least half of patients who died by suicide and two thirds of those who attempted suicide visited a GP in the preceding months, challenging the GPs' recognition and management of suicidal patients [11-13]. According to Milner's systematic review and meta-analysis, suicide prevention in primary care produced equivocal results [14]. One point has not yet been investigated: the involvement of primary-care professionals at the time of the $S A$. The role of emergency departments (EDs) has been more explored. A systematic review estimated that mental or behaviouralhealth disorders accounted for $4 \%$ of ED attendance and, among these, a third due to self-harm or suicidal ideation [15]. In standard practice in the ED, those who attempt suicide are either hospitalized or sent home after treatment and evaluation by a mental-health professional, with some variability in the organization according to country and setting [14-17]. We found few data on prehospital or primary care. A South-African study explored the attitudes of 130 prehospital providers (not including GPs) on transport decision in the management of SA patients who refuse care. They reported a critical lack of training and certain negative attitudes and difficulties [18]. For primary care, the position of GPs (patients' expectations and GPs' task performance regarding mental health care, role of others health actors) varies between health care systems. In more gatekeeping countries (as in Netherlands, Spain and the United Kingdom for example), a patient cannot consult a medical specialist directly and GPs' task could be different than in non- gatekeeping countries (as in Belgium, France, Germany, Canada and Switzerland) where patients may have direct access to specialists [19]. The Belgian Network of Sentinel General Practices reported several characteristics of SA encountered between 2013 and $2016(n=245)$, including one information about GP informant of suicide attempt $(n=241)$ and established that GP was on site as first caregiver following the SA for $N=46$ patients (19.1\%) [20]. The first aim of our study was to describe further, in another non-gatekeeping country, the role of GPs as first caregiver following the SA (how often, for which patients, and their management: how often GPs refer patients to the hospital, how often they give care in place of the hospital).

The aftercare of a SA is challenging, because of the high risk of subsequent suicide or all-cause mortality [21] and morbidity. Two of 10 patients repeat a SA during the first 5 years [22]. Active contact and follow-up has been shown to be effective in preventing a repeat $\mathrm{SA}$ in the first 12 months $(n=5319$; pooled $\mathrm{RR}=0.83$; 95\% CI: 0.71 to 0.97$)$. However, the effect at 24 months was not confirmed in EDs [23]. Studies conducted among patients registered in a general hospital in the UK for SA have reported the central role of primary care (gatekeeping system): approximately 30 to $40 \%$ consulted their GP in the week following a SA and 25 to $50 \%$ in the following month. Among them, $58 \%$ discussed the SA during the first consultation [7, 11, 24]. The rate of mental health treatment does not exceed $30-50 \%$, with a higher rate if the appointment was booked with a mental health professional before discharge [25]. A recent study conducted in Canada a non-gatekeeping country, reported a more limited role of primary care and a high frequency of patients without any care: among 23,140 individuals attending EDs for self-harm in a Canadian hospital, $10.7 \%$ consulted a GP for a mental-health visit within 1 month, $17.1 \%$ a psychiatrist, $3.6 \%$ both, and $68.6 \%$ had no care [22]. The role of primary care needs to be explored further. We aimed to describe how often and for which patients GPs provide aftercare following a SA and whether the role of GPs as first caregiver following the SA is associated with more aftercare by the GP. 
The objective of the present study is to describe primary care management 1) at the time of a SA and 2) after the SA.

\section{Methods}

\section{Population and procedure}

We studied "suicidal" patients from the French General Practice Sentinel Network from January 1, 2013 to December 31, 2016. The study was authorized by the scientific board of the Network. During the study period, 601 GPs throughout metropolitan France had continually reported online the occurrence of 10 health related events (including SA) on an unpaid volunteer basis at some point in their work week [26]. Sentinelles GPs practise like other French GPs. They are not different from other in term of age and practice of complementary medicine but slightly different regarding location, gender (female: $19 \%$ vs $29 \%$ ) and number of consultation per week (94 vs 92) [27]. We hypothesized that those minor differences won't have a major impact on our results regarding generalization to other SA seen by French GPs. For SA, GPs are instructed to report all cases they are confronted with in their daily practice, namely individuals seen while they are on duty or seen by other caregivers (mainly EDs) who belong to the GPs patient base. SAs are defined, from the WHO/EURO para-suicide definition of "suicidal acts of self-inflicted injury or selfpoisoning with drugs in excess of the generally recognized therapeutic dose, excluding non-suicidal selfinjury or self-poisoning" [28, 29].

The GPs report:

- the patients' sociodemographic data (for age, we considered three classes: < 34 years, 35 to 54 years, and $>55$ years) and clinical characteristics

- characteristics of the last consultation in primary care (time, expression of suicidal ideation) and their previous management: a) the presence of "psychological difficulties" or "depression" in the preceding year and the b) provision of psychological support, psychotropic drugs, referral to a psychiatrist or psychologist, and specialized care during the preceding 3 months,

- whether they managed the patient at home at the time of the SA,

- whether they managed the patient after the SA.

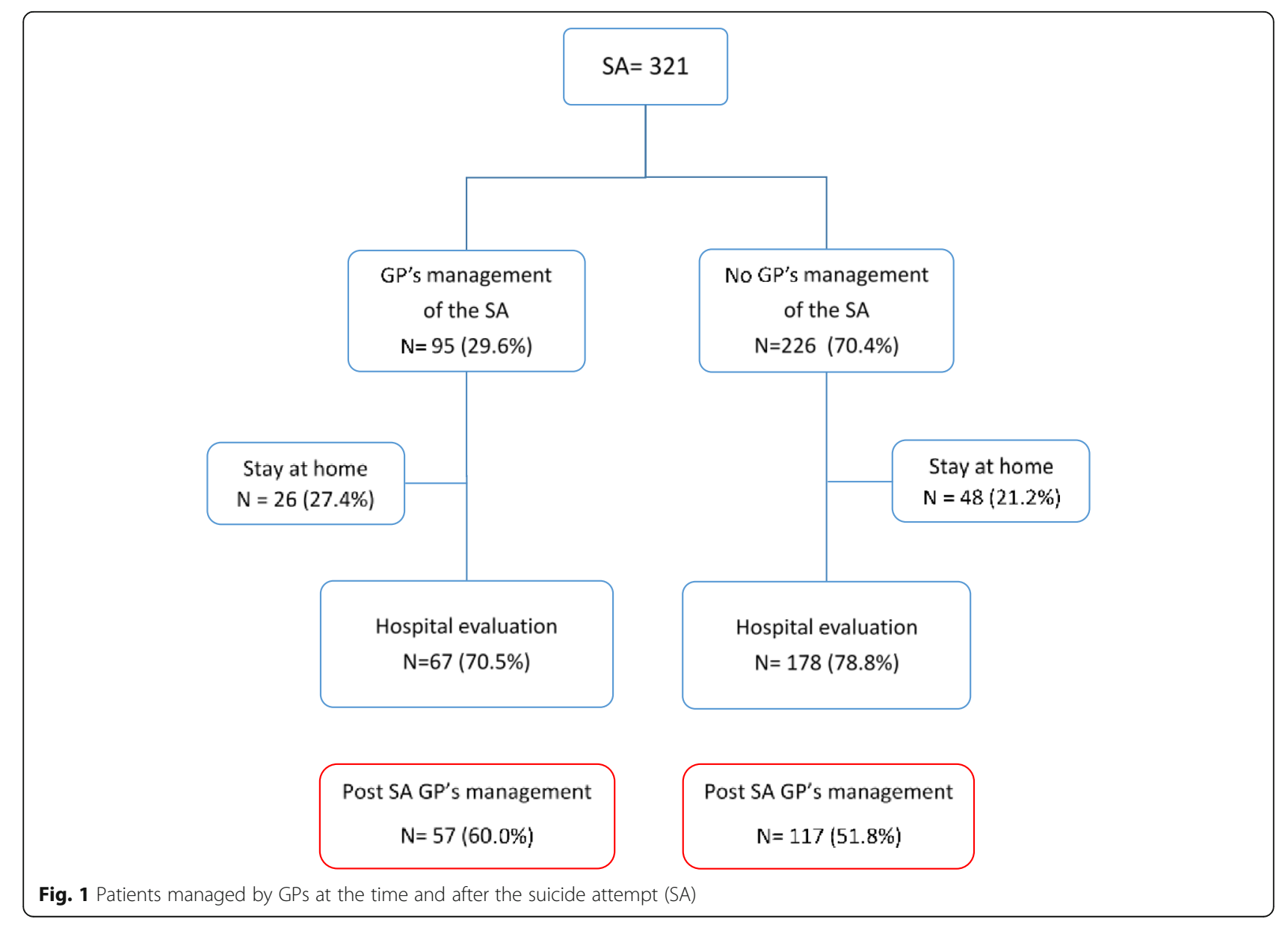


For this study, we considered only SAs (excluding SA that lead to suicide).

\section{Analysis}

Chi-square or Fischer tests were carried out to test for significant differences between GPs reporting SA and GPs not reporting SA in the French General Practice Sentinel Network. Descriptive analyses were used to report the management of the patients by the GP (Fig. 1). Chi-square or Fischer tests were carried out to test for significant differences between SAs managed by the GP or not, according to the patients' sociodemographic and clinical characteristics. Similarly, tests were carried out for post-SA management by GPs. We also computed odds ratios with a $95 \%$ confidence interval. $P$-values < 0.05 were considered to reach statistically significance.
All analyses were performed using GNU R software, version 3.1.1 [30].

\section{Ethics statement}

The French Sentinel general practice Network is approved by the National Data Protection Agency (CNIL, registration number \#47139). The protocol was conducted in agreement with the Helsinki Declaration. All GPs participants are volunteers to participate and they fulfilled questionnaires in line. They are informed about studies conducted from their medical charts. We performed an observational study on anonymous data without any way to identify patients. Patients are informed that their GP belongs to the Network. The ethics committee Comité de protection des personnes Ile de France V" « surveillance épidémiologique du réseau Sentinelles-C-11-15 » approved this procedure.

Table 1 Comparison of GPs reporting SA ( $N=166)$ and GPs not reporting SA ( $N=435)$ in the French General Practice Sentinel Network in 2013-2016 ( $N=601)$

\begin{tabular}{|c|c|c|}
\hline & $\begin{array}{l}\text { GPs reporting SA } \\
\boldsymbol{N}=166 \\
27.6 \% \\
N(\%)\end{array}$ & $\begin{array}{l}\text { GPs not reporting SA } \\
\boldsymbol{N}=435 \\
72.4 \% \\
N(\%)\end{array}$ \\
\hline \multicolumn{3}{|l|}{ Sex } \\
\hline Female & $49(29.5)$ & $117(26.9)$ \\
\hline Male & $117(70.5)$ & $318(73.1)$ \\
\hline Age in 2013 median (q1-q3) & $52(41-58)$ & $53(42-59)$ \\
\hline Length of medical practice (in 2013) median (q1-q3) & $19(5-17)$ & $21(7-29)$ \\
\hline Length of Sentinel practice (in 2013) median (q1-q3) & $5(1-15)$ & $6(0-15)$ \\
\hline \multicolumn{3}{|l|}{ Medical practice } \\
\hline Solo practitioner & $53(36.6)$ & $131(40.3)$ \\
\hline Group practitioner & $92(63.4)$ & $194(59.7)$ \\
\hline \multicolumn{3}{|l|}{ Practice setting } \\
\hline Urban & $126(75.9)$ & $346(79.7)$ \\
\hline Rural & $40(24.1)$ & $88(20.3)$ \\
\hline \multicolumn{3}{|l|}{ Region in France } \\
\hline Auvergne Rhone Alpes & $42(25.3)$ & $93(21.4)$ \\
\hline Bourgogne Franche Comté & $13(7.8)$ & $13(3.0)$ \\
\hline Bretagne & $12(7.2)$ & $21(4.8)$ \\
\hline Centre Val de Loire & $13(7.8)$ & $89(48.1)$ \\
\hline Corse & $27(38.0)$ & $24(5.5)$ \\
\hline Grand Est & $11(6.6)$ & $39(9.0)$ \\
\hline Hauts de France & $11(6.6)$ & $28(6.4)$ \\
\hline Ile de France & $16(9.6)$ & $58(1.3)$ \\
\hline Normandie & $6(3.6)$ & $18(4.1)$ \\
\hline Nouvelle Aquitaine & $8(4.8)$ & $29(6.7)$ \\
\hline Occitanie & $22(13.2)$ & $39(9.0)$ \\
\hline Pays de Loire & $4(2.4)$ & $17(3.9)$ \\
\hline Provence-Alpes-Côte d'Azur & $5(3.0)$ & $31(7.1)$ \\
\hline
\end{tabular}




\section{Results}

From January 2013 to December 2016, 321 SAs in primary care (for 312 patients estimated) were reported to the Sentinel network by 166 GPs. $N=435$ GPs did not encounter SAs among their patients at that time.

\section{GPs' reporting (Table 1)}

In the Sentinel Network, GPs not reporting SA $(N=$ 435) and GPs reporting SA $(N=166$, with $N=95$ GPs, $57.2 \%$ reported one SA, $N=35,21.1 \%$ reported two and $N=36,21.7 \%$ thee and more; $N=156$ GPs had a 2 months follow-up after the SA) did not differ. GPs were mainly men, about 50 y.o., with urban and group practice. They came from all the 13 administrative area in France.

\section{Patients managed by GPs at the time of the SA and after} (Fig. 1)

GPs were involved in the management of 95 (29.6\%) patients at the time of their SA. They referred most to the hospital for evaluation and management, but
$27.4 \%$ stayed home. GPs also reported that $14.9 \%$ of their patients who attempted suicide $(N=48)$ stayed home without care following their SA and $55.4 \%$ $(N=178)$ were managed at the hospital without their intervention.

Globally, hospital management was central for 245 (76.3\%) patients in primary care at the time of the SA (patients addressed to the ED by GPs or patients presenting directly to the ED). GPs reported a connection (written or oral) with the hospital for $N=115$ patients (46.9\%).

After the SA, GPs managed the care of 174 patients $(54.2 \%)$, more often $(60 \%)$ if they provided care at home at the time of the SA, $p=0.04 ; 1.87$ [1.07; 3.35].

Factors associated with care by GPs at the time of the SA and after (Tables 2 and 3)

At the time of the SA, GPs were more often involved in the care of their patients if they were younger $(39.2 \%$ for patients aged between 18 and 34 years vs $22.9 \%$ for those aged 35-54 years and 30.3\% for those older than 55

Table 2 Comparison of patients who attempted suicide managed or not by GPs at the time of the suicide attempt ( $N=321)$

\begin{tabular}{|c|c|c|c|c|}
\hline & $\begin{array}{l}\text { Managed by a GP } \\
\text { at the time of the SA } \\
N=95 \\
29.6 \% \\
N(\%)\end{array}$ & $\begin{array}{l}\text { Not managed by a GP } \\
\text { at the time of the SA } \\
N=226 \\
70.4 \% \\
N(\%)\end{array}$ & $p$ & OR $[95 \% \mathrm{Cl}]$ \\
\hline $\operatorname{Sex}(n=318)$ & & & ns & \\
\hline Female & $47(50.0)$ & $127(56.7)$ & & 1 \\
\hline Male & $47(50.0)$ & $97(43.3)$ & & $1.31[0.81-2.13]$ \\
\hline $\operatorname{Age}(n=321)$ & & & 0.02 & \\
\hline$<34$ yo & $38(40.0)$ & $59(26.1)$ & & 1 \\
\hline $35-54$ yo & $34(35.8)$ & $114(50.4)$ & & $0.47[0.26-0.81]$ \\
\hline$\geq 55$ yo & $23(24.2)$ & $53(23.5)$ & & $0.68[0.35-1.28]$ \\
\hline Suicidal methods used $(n=308)$ & & & 0.006 & \\
\hline Drugs & $51(56.7)$ & $164(75.2)$ & & 1 \\
\hline Self-cutting & $14(15.5)$ & $13(6.0)$ & & $3.44[1.50-7.94]$ \\
\hline Hanging and firearm & $8(8.9)$ & $15(6.9)$ & & $1.72[0.65-4.25]$ \\
\hline Others (downing, falls, etc) & $17(18.9)$ & $26(11.9)$ & & $2.10[1.04-4.17]$ \\
\hline History of previous attempts ( $n=286$ ) & $36(42.4)$ & $82(40.8)$ & ns & $1.07[0.63-1.78]$ \\
\hline Suicidal ideas expressed at the last consultation $(n=260)$ & $34(46.6)$ & $79(42.2)$ & ns & $1.19[0.69-2.06]$ \\
\hline Time of the last consultation $(n=261)$ & & & ns & \\
\hline$<1$ month & $45(60.8)$ & $102(54.5)$ & & 1 \\
\hline$\geq 1$ month & $29(39.2)$ & $85(45.5)$ & & $0.77[0.44-1.34]$ \\
\hline \multicolumn{5}{|l|}{ GP management in the last three months $(n=262)$} \\
\hline Psychological support & $32(44.4)$ & $80(43.4)$ & ns & $1.02[0.59-1.77]$ \\
\hline Antidepressant prescriptions & $26(36.1)$ & $75(41.0)$ & ns & $0.82[0.46-1.43]$ \\
\hline Other psychotropic drug prescriptions & $32(44.4)$ & $99(53.2)$ & ns & $0.70[0.40-1.22]$ \\
\hline Attempted referral to a mental-health specialist & $33(47.1)$ & $89(48.1)$ & ns & $0.96[0.55-1.67]$ \\
\hline Parallel care with a mental health specialist & $27(38.0)$ & $73(39.2)$ & ns & $0.95[0.54-1.67]$ \\
\hline
\end{tabular}


Table 3 Comparison of patients who attempted suicide managed or not by a GP after the suicide attempt (SA) $(N=281)$

\begin{tabular}{|c|c|c|c|c|}
\hline & $\begin{array}{l}\text { Managed by a GP } \\
\text { after the SA } \\
N=174 \\
61.9 \% \\
N(\%) \\
\end{array}$ & $\begin{array}{l}\text { Not managed by a GP } \\
\text { after the SA } \\
N=107 \\
38.1 \% \\
N(\%) \\
\end{array}$ & $p$ & OR $[95 \% \mathrm{Cl}]$ \\
\hline $\operatorname{Sex}(n=279)$ & & & ns & \\
\hline Female & $94(54.0)$ & $62(59.0)$ & & 1 \\
\hline Male & $80(46.0)$ & $43(41.0)$ & & $1.22[0.75-2.01]$ \\
\hline Age $(n=281)$ & & & ns & \\
\hline$<34$ yo & $50(28.7)$ & $34(31.8)$ & & 1 \\
\hline $35-54$ yо & $79(45.4)$ & $57(53.3)$ & & $0.94[0.54-1.64]$ \\
\hline$>=55$ yo & $45(25.9)$ & $16(14.9)$ & & $1.90[0.93-3.98]$ \\
\hline Suicidal methods used $(n=270)$ & & & ns & \\
\hline Drugs & $111(66.9)$ & $79(76.7)$ & & 1 \\
\hline Self-cutting & $16(9.6)$ & $8(7.8)$ & & $1.41[0.58-3.67]$ \\
\hline Hanging and firearm & $15(9.0)$ & $4(3.9)$ & & $2.59[0.89-9.62]$ \\
\hline Others & $24(14.5)$ & $12(11.6)$ & & $1.41[0.68-3.10]$ \\
\hline History of previous attempts $(n=251)$ & $62(38.7)$ & $41(45.0)$ & ns & $0.77[0.46-1.30]$ \\
\hline Suicidal ideas expressed at the last consultation $(n=228)$ & $69(48.9)$ & $34(39.1)$ & ns & $1.49[0.87-2.58]$ \\
\hline Time of the last consultation $(n=228)$ & & & ns & \\
\hline$<1$ month & $84(59.6)$ & $43(49.4)$ & & 1 \\
\hline$\geq 1$ month & $57(40.4)$ & $44(50.6)$ & & $0.66[0.39-1.14]$ \\
\hline \multicolumn{5}{|l|}{ GP management in the last three months $(n=230)$} \\
\hline Psychological support & $66(47.8)$ & $32(38.1)$ & ns & $1.48[0.85-2.60]$ \\
\hline Antidepressant prescriptions & $59(41.8)$ & $34(40.0)$ & ns & 1.10 [0.64-1.93] \\
\hline Other psychotropic drug prescriptions & $76(54.3)$ & $38(43.7)$ & ns & $1.53[0.89-2.63]$ \\
\hline Attempted referral to a mental-health specialist & $66(48.2)$ & $43(50.0)$ & ns & $0.93[0.54-1.60]$ \\
\hline Parallel care with a mental-health specialist & $59(42.4)$ & $31(35.6)$ & ns & $1.33[0.77-2.33]$ \\
\hline Managed by a GP at the time of the SA $(n=281)$ & & & 0.04 & \\
\hline No & $117(67.2)$ & $85(79.4)$ & & 1 \\
\hline Yes & $57(32.8)$ & $22(20.6)$ & & $1.87[1.07-3.35]$ \\
\hline
\end{tabular}

years; $p=0.02$, with respective ORs of $1,0.47[0.26-$ $0.81]$, and $0.68[0.35-1.28])$ and if the method of the SA was self-cutting versus drugs $(\mathrm{OR}=3.44[1.50-7.94] ; p=$ 0.06). No other factors (sex and clinical characteristics, expression of suicidal ideas at the last consultation, or previous mental health management in primary care) were associated with the patient being managed by a GP at the time of the SA.

No factor was associated with the SA patients staying at home without care or those addressed by GPs to hospitals.

Post-SA patients managed by a GP were not associated with factors, except when the SA was managed by the GP at the time of the SA. Patients managed by the GP at the time of the SA were more likely to have aftercare by the GP, $p=0.04 ; 1.87$ [1.07; 3.35].

\section{Discussion}

GPs were first caregiver following the SA for $29.6 \%$ of their patients (more if the patients were younger or they used self-cutting for their SA). They referred two-thirds to hospitals and one third remained at home. Connections between GPs and ED upon discharge occurred for $46.9 \%$ of patients.

After the SA, GPs were consulted by $54.2 \%$ of their SA patients, more often when GPs were first caregiver following the SA.

\section{GP as first caregiver following the SA}

We found a similar (event slightly higher) percentage than in the study conducted in another non-gatekeeping country by the Belgian Network of Sentinel General Practices [20]. It concerns a minority of patients: 
most SAs were managed by other prehospital providers, such as firemen or family [18] and EDs [15]. It is interesting to note that most patients managed by their GP at the time of SA were referred to the hospital. Our study was quantitative and did not explore difficulties encountered by GPs as prehospital or first providers. GPs may face certain difficult situations, such as patients refusing care or having limited confidence to make decisions in such situations, as described elsewhere among other providers [18].

GPs were more frequently the first caregiver for younger patients and in cases of SA using self-cutting, compared to self-poisoning which was more associated with hospital management and admission [31].

We did not find any factors that differentiated between patients who stayed at home and those addressed to hospitals for SAs managed by the GPs at home, possibly due to a lack of statistical power.

Our study also measured the frequency of patients who attempted suicide who did not seek help (approximately 15\%), which has not yet been explored in the context of primary-care recruitment. A higher rate (26.8\%) has been reported for the general French population by the Baromètre Santé [32]; the difference lies in the survey methodology and target population. Moreover, GPs in our survey may have been unaware of some SAs. One of the major obstacles hindering the help-seeking process is the refusal by the suicide attempter to receive professional care and the "help-seeking road travelled by the significant others of a suicide attempter is, in most cases, tortuous and difficult" [33]. Patients may conceal suicidality because of stigmatization [34]. More women seek help [32] but we did not find this result in our survey.

\section{Patient management by GPs after the SA}

Our results confirmed the central place of primary care in the aftercare of SA patients [7, 11, 24], but also the high frequency of those who reveive no care after a SA [22]. Brief contact interventions for any patient leaving the ED after a SA, to help to cope with any new suicidal crisis could be reliable suicide prevention strategies, could be reliable suicide prevention strategies, in collaboration with GPs [23, 35, 36].

We did not find any factors associated with such aftercare, except whether the patient was managed by the GP at the time of the SA, with a higher frequency of patients who received aftercare by the GP if the GP was the first caregiver following the SA. This result may be related to a stronger physician-patient-family working alliance [37, 38].

Connection between GPs and ED upon discharge (47\%) is lower than found in another non-gatekeeping country [20] and should be improved as GPs are central after the SA.

\section{Strengths and limitations of the study}

The main strength of this study was the data from the Sentinelles Network, which allowed the assessment of all SAs encountered in the primary-care setting over a fouryear period.

Our study also had several limitations. First, a selection bias. SAs may have been underreported by GPs, who forget to report them or may not have been aware of some suicidal acts (for suicide attempts that did not lead to a medical intervention, especially among patients less involved in primary care and with less aftercare [7, 9, 10, 39, 40]). Participation was, however, comparable to that reported for the two other existing GeneralPractice Sentinel Networks [9, 20, 41, 42]. Second, Sentinelles GPs may not reflect the practices of French GPs, as their involvement in the Network may make them more aware of certain problems, such as SAs [43]. Third, some data that could impact the management in primary care were unfortunately not measured: SA management by other prehospital providers, information about a management in secondary care,... Finally, results are valid for a non-gatekeeping health system.

\section{Conclusion}

For the first time, we described primary care management at the time of a SA and after the SA in France (a non-gatekeeping health system). GPs were first caregiver following the SA for a minority of patients and they referred to hospitals two-thirds of them. The place of other prehospital providers, such as firemen or family [18] and EDs [15] is more common. Primary care management is important after the SA (more than half patients, more often when GPs were first caregiver following the SA). However, about half patients did not receive care after a SA [22]. Brief contact interventions for any patient leaving the ED after a SA, to help to cope with any new suicidal crisis could be reliable suicide prevention strategies [23, 36]. Connections between GPs and ED upon discharge should be improved.

\section{Abbreviations \\ GP: General practitioner; SA: Suicide attempt; ED: Emergency department; RR: Relative risk; WHO: World health organization}

\section{Acknowledgements \\ We thank all sentinel GPs for participating in the study and completing the questionnaires.}

\section{Authors' contributions}

NY, MR, and CCC designed the study and the GP questionnaire. MR and RP performed the data analysis. NY drafted the manuscript. MR, TH, LR, TB, FU and CCC made critical revisions and edited the manuscript. All authors contributed to and approved the final manuscript. 


\section{Funding}

This research received no specific grant from any funding agency in the public, commercial or not-for-profit sectors. We thank the Centre Hospitalier de Versailles for editorial assistance.

\section{Availability of data and materials \\ At the corresponding authors.}

\section{Ethics approval and consent to participate}

The French Sentinelles general practice Network is approved by the National Data Protection Agency (CNIL, registration number \#47139). The protocol was conducted in agreement with the Helsinki Declaration. All GPS participants are volunteers to participate and they fulfilled questionnaires in line. They are informed about studies conducted from their medical charts. We performed an observational study on anonymous data without any way to identify patients. Patients are informed that their GP belongs to the Network. The ethics committee Comité de protection des personnes lle de France $V$ " "surveillance épidémiologique du réseau Sentinelles-C-11-15 » approved this procedure.

\section{Consent for publication}

Not applicable.

\section{Competing interests}

The authors declare they have no competing interests.

\section{Author details}

${ }^{1}$ EA 40-47 Université Versailles Saint-Quentin-en-Yvelines, F-78047 Guyancourt, France. ${ }^{2}$ Versailles Hospital, Academic Unit of Psychiatry, 177 Rue de Versailles, 78157 Le Chesnay, Cedex, France. ${ }^{3}$ Université

Versailles-Saint-Quentin-en-Yvelines, Versailles, France. ${ }^{4}$ Sorbonne Université, INSERM, Pierre Louise Institute of Epidemiology and Public Health, F-75013 Paris, France. ${ }^{5}$ Infectious Disease Department, CHR Orléans La Source, Orléans, France. ${ }^{6}$ French Institute for Public Health Surveillance, Saint Maurice, France.

\section{Received: 2 October 2019 Accepted: 11 March 2020}

Published online: 25 March 2020

\section{References}

1. Nock MK, Borges G, Bromet EJ, Cha CB, Kessler RC, Lee S. Suicide and suicidal behavior. Epidemiol Rev. 2008:30:133-54 PubMed PMID: 18653727. Pubmed Central PMCID: PMC2576496. Epub 2008/07/26. eng.

2. Badeyan GP, C. Suicide and attempted suicide in France. Etudes et résultats. 2001;109:1-8

3. Chan Chee CJ-S, D. Hospitalisations pour tentatives de suicide entre 2004 et 2007 en France métropolitaine. Analyse du PMSI-MCO. BHE. 2011:47-48: 492-6.

4. Bernal M, Haro JM, Bernert S, Brugha T, de Graaf R, Bruffaerts R, et al. Risk factors for suicidality in Europe: results from the ESEMED study. J Affect Disord. 2007;101(1-3):27-34 PubMed PMID: 17074395. Epub 2006/11/01. eng.

5. Olfson M, Weissman MM, Leon AC, Sheehan DV, Farber L. Suicidal ideation in primary care. J Gen Intern Med. 1996;11(8):447-53 PubMed PMID: 8872781.

6. Younes N, Riviere M, Plancke L, Leroyer A, Blanchon T, Azevedo Da Silva M, et al. Work intensity in men and work-related emotional demands in women are associated with increased suicidality among persons attending primary care. J Affect Disord. 2018;235:565-73 PubMed PMID: 29698918. Epub 2018/04/27. eng.

7. Gunnell D, Bennewith O, Peters TJ, Stocks N, Sharp DJ. Do patients who self-harm consult their general practitioner soon after hospital discharge? A cohort study. Soc Psychiatry Psychiatr Epidemiol. 2002;37(12):599-602 PubMed PMID: 12545238. Epub 2003/01/25. eng

8. Poma SZ, Grossi A, Toniolo E, Baldo V, Leo DD. Self-perceived difficulties with suicidal patients in a sample of Italian general practitioners. J Clin Med Res. 2011;3(6):303-8 PubMed PMID: 22393342. Pubmed Central PMCID: PMC3279475. Epub 2012/03/07. eng.

9. Marquet RL, Bartelds Al, Kerkhof AJ, Schellevis FG, van der Zee J. The epidemiology of suicide and attempted suicide in Dutch general practice 1983-2003. BMC Fam Pract. 2005;6:45 PubMed PMID: 16271136.
10. Riihimaki K, Vuorilehto M, Melartin T, Haukka J, Isometsa E. Incidence and predictors of suicide attempts among primary-care patients with depressive disorders: a 5-year prospective study. Psychol Med. 2014;44(2):291-302 PubMed PMID: 23570583. Epub 2013/04/11. eng.

11. Houston K, Haw C, Townsend E, Hawton K. General practitioner contacts with patients before and after deliberate self harm. Br J Gen Pract : J R Coll Gen Pract. 2003;53(490):365-70 PubMed PMID: 12830563. Pubmed Central PMCID: PMC1314595. Epub 2003/07/02. eng.

12. Raue PJ, Brown EL, Meyers BS, Schulberg HC, Bruce ML. Does every allusion to possible suicide require the same response? J Fam Pract. 2006;55(7):60512 PubMed PMID: 16822448

13. De Leo D, Draper BM, Snowdon J, Kolves K. Contacts with health professionals before suicide: missed opportunities for prevention? Compr Psychiatry. 2013: 54(7):1117-23 PubMed PMID: 23768696. Epub 2013/06/19. eng.

14. Milner A, Witt K, Pirkis J, Hetrick S, Robinson J, Currier D, et al. The effectiveness of suicide prevention delivered by GPs: a systematic review and meta-analysis. J Affect Disord. 2017;210:294-302 PubMed PMID: 28068618. Epub 2017/01/10. eng.

15. Barratt H, Rojas-Garcia A, Clarke K, Moore A, Whittington C, Stockton S, et al. Epidemiology of mental health attendances at emergency departments: systematic review and meta-analysis. PLoS One. 2016;11(4):e0154449 PubMed PMID: 27120350. Pubmed Central PMCID: PMC4847792. Epub 2016/04/28. eng.

16. Baraff $L$, Janowicz N, Asarnow JR. Survey of California emergency departments about practices for management of suicidal patients and resources available for their care. Ann Emer Med. 2006;48(4):452-8 8 e1-2. PubMed PMID: 16997683. Epub 2006/09/26. eng.

17. Kudo K, Otsuka K, Endo J, Yoshida T, Isono H, Yambe T, et al. Study of the outcome of suicide attempts: characteristics of hospitalization in a psychiatric ward group, critical care center group, and non-hospitalized group. BMC Psychiatry. 2010;10:4 PubMed PMID: 20064269. Pubmed Central PMCID: PMC2821663. Epub 2010/01/13. eng.

18. Evans K, Geduld H, Stassen W. Attitudes of prehospital providers on transport decision-making in the management of patients with a suicide attempt refusing care: A survey based on the Mental Health Care Act of 2002. S Afr J Psychiatry : SAJP : J Soc Psychiatry S Afr. 2018;24:1156 PubMed PMID: 30473879. Pubmed Central PMCID: PMC6244439 may have inappropriately influenced them in writing this article. Epub 2018/11/27. eng.

19. France SP. Prévenir le suicide : connaissances et interventions. La Santé en action : prévention, promotion, éducation. 2019 décembre 2019;450.

20. Boffin N, Van Casteren V, De Ridder K. Care of general practice patients preceding and following a suicide attempt: observational study in Flemish general practices. BMJ Open. 2019;9(5):e028546 PubMed PMID: 31061060. Pubmed Central PMCID: PMC6501981. Epub 2019/05/08. eng.

21. Steeg S, Carr M, Emsley R, Hawton K, Waters K, Bickley H, et al. Suicide and all-cause mortality following routine hospital management of self-harm: Propensity score analysis using multicentre cohort data. PloS One. 2018;13(9):e0204670 PubMed PMID: 30261030. Pubmed Central PMCID: PMC6161837 Suicide Prevention Advisory Group. N.K. chaired the NICE guideline development group for the longer-term management of self-harm and the NICE Topic Expert Group (which developed the quality standards for self-harm services). He is currently chair of the updated NICE guideline for depression. All other authors declare no conflict of interest. This does not alter our adherence to all the PLOS ONE policies on sharing data and materials, as detailed online in the guide for authors. Epub 2018/09/28. eng.

22. Hunter J, Maunder R, Kurdyak P, Wilton AS, Gruneir A, Vigod S. Mental health follow-up after deliberate self-harm and risk for repeat self-harm and death. Psychiatry Res. 2018;259:333-9 PubMed PMID: 29120839. Epub 2017/11/10. eng.

23. Inagaki M, Kawashima Y, Kawanishi C, Yonemoto N, Sugimoto T, Furuno T, et al. Interventions to prevent repeat suicidal behavior in patients admitted to an emergency department for a suicide attempt: a meta-analysis. J Affect Disord. 2015;175:66-78 PubMed PMID: 25594513. Epub 2015/01/17. eng.

24. Kapur N, House A, Creed F, Feldman E, Friedman T, Guthrie E. Management of deliberate self poisoning in adults in four teaching hospitals: descriptive study. BMJ (Clin Res ed). 1998;316(7134):831-2 PubMed PMID: 9549454. Pubmed Central PMCID: PMC28487. Epub 1998/04/29. eng.

25. Costemale-Lacoste JF, Balaguer E, Boniface B, Ivascu EB, Bernardini C, Metton JP, et al. Outpatient treatment engagement after suicidal attempt: a multisite prospective study. Psychiatry Res. 2017;258:21-3 PubMed PMID: 28982037. Epub 2017/10/06. eng.

26. Valleron AJ, Garnerin P. Computer networking as a tool for public health surveillance: the French experiment. MMWR Morb Mortal Wkly Rep. 1992; 41(Suppl):101-10 PubMed PMID: 1344245. 
27. Souty C, Turbelin C, Blanchon T, Hanslik T, Le Strat Y, Boelle PY. Improving disease incidence estimates in primary care surveillance systems. Popul Health Metrics. 2014;12:19 PubMed PMID: 25435814. Pubmed Central PMCID: PMC4244096. Epub 2014/12/02. eng.

28. Le Pont F, Letrilliart L, Massari V, Dorleans Y, Thomas G, Flahault A. Suicide and attempted suicide in France: results of a general practice sentinel network, 1999-2001. The British journal of general practice : the journal of the Royal College of General Practitioners. 2004;54(501):282-4 PubMed PMID: 15113496.

29. Platt S, Bille-Brahe U, Kerkhof A, Schmidtke A, Bjerke T, Crepet P, et al. Parasuicide in Europe: the WHO/EURO multicentre study on parasuicide. I. Introduction and preliminary analysis for 1989. Acta Psychiatr Scand. 1992; 85(2):97-104 PubMed PMID: 1543046.

30. Team RDC. R: a language and environment for statistical computing Vienna. R Foundation for Statistical Computing: Austria; 2008. Available from: http:// www.R-project.org.

31. Gunnell D, Bennewith O, Peters TJ, House A, Hawton K. The epidemiology and management of self-harm amongst adults in England. J Public Health (Oxf). 2005;27(1):67-73 PubMed PMID: 15564277. Epub 2004/11/27. eng.

32. Léon C, Chan-chee C, Du Roscoät E. Baromètre de Santé publique France 2017: tentatives de suicide et pensées suicidaires chez les 18-75 ans. Bulletin Epidémiologique Hebdomadaire. 2019;(3-4):38-47. https:// portaildocumentaire.santepubliquefrance.fr/exl-php/vue-consult/spf__ internet_recherche/SPF00000634.

33. Castelli Dransart DA, Guerry S. Help-seeking in suicidal situations: paramount and yet challenging. Interactions between significant others of suicidal persons and health care providers. J Clin Med. 2017;6(2):1-14. https://doi. org/10.3390/jcm6020017. PubMed PMID: 28208800; PubMed Central PMCID: PMC5332921.

34. Han J, Batterham PJ, Calear AL, Randall R. Factors influencing professional help-seeking for Suicidality. Crisis. 2018;39(3):175-96 PubMed PMID: 29052431. Epub 2017/10/21. eng

35. Vaiva $G$, Berrouiguet $S$, Walter $M$, Courtet $P$, Ducroca F, Jardon V, et al. Combining postcards, crisis cards, and telephone contact into a decisionmaking algorithm to reduce suicide reattempt: a randomized clinical trial of a personalized brief contact intervention. J Clin Psychiatry. 2018;79(6) PubMed PMID: 30256552. Epub 2018/09/27. eng.

36. Milner AJ, Carter G, Pirkis J, Robinson J, Spittal MJ. Letters, green cards, telephone calls and postcards: systematic and meta-analytic review of brief contact interventions for reducing self-harm, suicide attempts and suicide. The British journal of psychiatry : the journal of mental science. 2015;206(3): 184-90 PubMed PMID: 25733570. Epub 2015/03/04. eng.

37. Fuertes JN, Toporovsky A, Reyes M, Osborne JB. The physician-patient working alliance: theory, research, and future possibilities. Patient Educ Couns. 2017;100(4):610-5 PubMed PMID: 27773600. Epub 2016/10/25. eng.

38. Kristjansson E, Hogg W, Dahrouge S, Tuna M, Mayo-Bruinsma L, Gebremichael G. Predictors of relational continuity in primary care: patient, provider and practice factors. BMC Fam Pract. 2013;14:72 PubMed PMID: 23 725212. Pubmed Central PMCID: PMC3688290. Epub 2013/06/04. eng.

39. Matthews K, Milne S, Ashcroft GW. Role of doctors in the prevention of suicide: the final consultation. Br J Gen Pract : J R Coll Gen Pract. 1994; 44(385):345-8 PubMed PMID: 8068391.

40. Simon GE, VonKorff M. Suicide mortality among patients treated for depression in an insured population. Am J Epidemiol. 1998;147(2):155-60 PubMed PMID: 9457005.

41. Bossuyt N, Van Casteren V. Epidemiology of suicide and suicide attempts in Belgium: results from the sentinel network of general practitioners. Int J Public Health. 2007:52(3):153-7 PubMed PMID: 17958281

42. Elzinga E, Gilissen R, Donker GA, Beekman ATF, de Beurs DP. Discussing suicidality with depressed patients: an observational study in Dutch sentinel general practices. BMJ Open. 2019;9(4):e027624 PubMed PMID: 31023763. Pubmed Central PMCID: PMC6501984. Epub 2019/04/27. eng.

43. Burless $C$, De Leo D. Methodological issues in community surveys of suicide ideators and attempters. Crisis. 2001;22(3):109-24 PubMed PMID: 11831598. Epub 2002/02/08. eng.

\section{Publisher's Note}

Springer Nature remains neutral with regard to jurisdictional claims in published maps and institutional affiliations.

\section{Ready to submit your research? Choose BMC and benefit from:}

- fast, convenient online submission

- thorough peer review by experienced researchers in your field

- rapid publication on acceptance

- support for research data, including large and complex data types

- gold Open Access which fosters wider collaboration and increased citations

- maximum visibility for your research: over $100 \mathrm{M}$ website views per year

At $\mathrm{BMC}$, research is always in progress.

Learn more biomedcentral.com/submissions 